\title{
Homa-Ir Insulin Resistance in Differentiated Thyroid Cancer and Benign Thyroid Nodules
}

Eloisa Castillo-Saavedra ( $\nabla$ elosaavedra@hotmail.com )

Instituto Mexicano del Seguro Social

Juan José Castillo-Dávila

Instituto Mexicano del Seguro Social

Dania Lizet Quintanilla-Flores

Institute for Social Security and Services for State Workers

Anally Jamile Soto-García

Centro Médico Hidalgo

\section{Research Article}

Keywords: Insulin Resistance, Differentiated Thyroid Cancer, Thyroid Nodules

Posted Date: December 22nd, 2021

DOI: https://doi.org/10.21203/rs.3.rs-1182497/v1

License: @ (i) This work is licensed under a Creative Commons Attribution 4.0 International License. Read Full License 


\section{Abstract}

Introduction: There is evidence that insulin resistance is associated with different types of cancer. This resistance increases the incidence of benign thyroid nodules and the risk of developing Differentiated Thyroid Cancer, however, studies in this regard are required.

Objective: To assess if there are differences in the prevalence of insulin resistance in patients with differentiated thyroid cancer and patients with benign thyroid nodule.

Material and methods: Prospective, analytical and cross-sectional design study. Patients undergoing thyroidectomy and definitive diagnosis of differentiated thyroid cancer or benign thyroid nodule were included. Anthropometric and biochemical variables were evaluated and differences in prevalence of insulin resistance were identified. To compare continuous variables, Student's T or Mann Whitney's U was used. To evaluate differences in categorical variables, the two-sided Fisher test when two binary variables were contrasted and Pearson's X2 in variables with more than two categories. Factors were analyzed through multivariate analysis obtaining odds ratio and $95 \%$ confidence interval.

Results: A lower possibility of cancer was concluded: hereditary-family history of thyroid disease and hypothyroidism (OR 0.159; 95\% Cl 0.038-0.669; $p=0.012)$. Positive HOMA-IR showed a significant association in residual structural disease $(P=0.050)$ and local vascular invasion $(p=0.014)$.

Conclusions: No significant association was obtained between positive HOMA-IR and Differentiated Thyroid Cancer, compared with the Benignity group. It seems that there is a greater tendency to lack of structural and biochemical resolution in patients with malignancy and positive HOMA-IR.

\section{Introduction}

With the increase in prevalence of the current Obesity and Diabetes Mellitus pandemic at global level, there has been a notable increase in different types of Cancer. Therefore, it is of particular importance for Endocrinology, to assess whether Insulin Resistance, as a pathophysiological basis for multiple comorbidities, also exerts an influence on the increase in cases of Differentiated Thyroid Cancer. Crosssectional studies have found an association of Insulin Resistance with thyroid nodular disease, justifying the mitogenic role of stimulation by IGF-I and TSH, but there are no conclusive results regarding the relationship of Insulin Resistance and Differentiated Thyroid Cancer. Insulin resistance (IR) is a pathological condition characterized by a decrease in the efficiency of insulin signaling for the regulation of serum glucose. It is an important component of the metabolic syndrome, that is, a group of risk factors that generally occur together and increase the risk of various diseases, including Type 2 Diabetes Mellitus, Cerebrovascular Disease and Coronary Syndromes, Neurodegenerative Disorders, Infectious Diseases and Cancer. Hyperinsulinemia resulting from the body's attempt to compensate for insulin resistance in different disease states such as type 2 diabetes and obesity favors the growth of insulinsensitive neoplastic tissue through increased signaling of the similar growth factor receptor to insulin (IGF-IR: abbreviation of English "Insulin Growing Factor I Receptor"). ${ }^{1}$ 
The mechanism this tumor activity occurs after the binding of ligand to the receptors with Tyrosine Kinase Activity for Insulin-Like Peptides, it leads to the phosphorylation of Substrates-IR in the cell membrane which in turn have different intracellular signaling mechanisms. ${ }^{2}$

- The activation of B isoform of insulin receptor, regulates Glucose homeostasis. ${ }^{3}$

- Activates the Ras/MAPK signaling pathway and the extracellular pathways related to Kinase 1/2 (ERK-1/2), associated with cancer cell growth and carcinogenesis. ${ }^{3}$

- It activates Phosphoinositide 3 Kinase (PI3K), with the consequent activation of Protein Kinase B (Akt) and that secondarily has 3 different action routes: first, target of rapamycin in mammalian cells or mTOR; second, the transcription factors Forkhead O (FoxO), and; third, inactivates Glycogen Synthase Kinase 3b (GSK3b), the inhibitor of oncogenic beta-catenin signaling, resulting in the activation of beta-catenin signaling that has been associated with cancer potency and chemoresistance. $^{3-5}$

- The IGF-II receptor attenuates IGF-II signaling by removing that molecule from the cell surface without signal transduction. ${ }^{6}$

In thyroid cancer, an association with insulin resistance has been proposed, although this association has not been firmly defined. ${ }^{7}$ In a retrospective study of a population database in Korea, it was found that the incidence of differentiated thyroid cancer was higher in patients without use of metformin, compared to patients with use of this drug. ${ }^{8}$

Saghier et al in a group of euthyroid patients with Thyroid Nodular Disease found that $56.70 \%$ of the subjects studied had HOMA-IR levels> 2.7, which denoted significant Insulin Resistance. No significant differences were found between subjects with and without IR in terms of thyroid profile. ${ }^{9}$ However, subjects with IR had more frequent thyroid nodules as well as increased Thyroid and Nodular Volume. Among the parameters studied, the multivariate linear regression analysis revealed that Thyroid Volume was mainly associated with higher levels of Serum Insulin and HOMA-IR index $(p=<0.000$ and $p=$ $<0.002$, respectively). The main predictors of development of more than one nodule were BMI, Serum Insulin, Thyroid Volume and HOMA-IR index. ${ }^{10}$ Our objective is to assess if there are differences in the prevalence of insulin resistance in patients with differentiated thyroid cancer and patients with benign thyroid nodule, and compare characteristics in the cancer group based on positive or negative HOMA-IR.

\section{Methods}

\section{Trial design}

Prospective, analytical and cross-sectional.

\section{Location}


Patients of the Department of Endocrinology of the Hospital de Especialidades Unidad Médica de Alta Especialidad. Número 25, Instituto Mexicano del Seguro Social, Monterrey, Nuevo León, México.

\section{Sample size}

the sample size was calculated for convenience, admitting patients attended during established period of time, who met the criteria for study.

\section{Participant}

We include population over 18 years of age, male and female gender, with the consent by the patients (or legal representative) to participate in the trial by signing the informed consent. The subjects undergoing thyroidectomy with definitive histopathological diagnosis of differentiated thyroid cancer or benign thyroid nodule (follicular adenoma). We exclude subjects with hypothyroidism or hyperthyroidism prior to the diagnosis of differentiated thyroid cancer or benign nodules, patients with use of medications indicated for weight loss, steroid use or with a diagnosis of concomitant malignant tumors, acromegaly, or under study for hypoglycemia.

\section{Factors analyzed:}

Insulin resistance it's a pathological condition characterized by a decrease in the efficiency of insulin signaling for the regulation of serum glucose. It was considered with a HOMA-IR Index greater than 2.5. Differentiated Thyroid Cancer it's a Malignant Neoplasia that develops in follicular cells of the thyroid gland and is confirmed by anatomopathological study in 2 lines: papillary or follicular thyroid cancer. Benign Thyroid Nodule are lesions in the thyroid gland, ultrasonographical different from the surrounding thyroid parenchyma. Fasting Serum Insulin, it's a polypeptide hormone of 51 amino acids secreted by beta cells of the pancreas with anabolic actions. Normal Serum Values of $8.7 \pm 3.2 \mu \mathrm{U} / \mathrm{mL}$ were taken. Fasting Serum Glycemia it's free serum glucose concentration during abstinence from food intake in a period of 8 hours, with normal values between $70-125 \mathrm{mg} / \mathrm{dl}$. Overweight and obesity it's an abnormal or excessive accumulation of fat that can be harmful to health. A Body Mass Index 25-29.9 was considered in this classification and $\geq 30$ for obesity. Waist Measurement it's the perimeter that allows estimating body fat at the level of the abdomen considering an abnormal value, women $>80 \mathrm{~cm}$ and men $>90 \mathrm{~cm}$. Waist-Hip Ratio results from dividing the perimeter of a person's waist by the perimeter of their hips and provides information on the risk of suffering from cardiovascular disease as a consequence of being overweight. Normal Value 0.8 for women and 0.9 for men Autoimmune Thyroid Disease it's the presence of antibodies against the compound thyroid peroxidase present in the bloodstream positive with Antiperoxidase Antibodies $>40 \mathrm{IU} / \mathrm{ml}$. 


\section{Intervention:}

All patients who underwent thyroidectomy with a pathological result of differentiated thyroid cancer or benign thyroid nodule were included. A medical history was taken in both groups and it was assessed that they met the inclusion and exclusion criteria. After reviewing the inclusion criteria, patients were invited to participate in the trial, informing what it consisted, its benefits and complications, and requesting the signing of the Letter of Informed Consent. A review of the clinical record was carried out and epidemiological, demographic, clinical and biochemical data were analyzed. Gender, age, family history related to thyroid diseases, smoking, alcoholism, drug addiction, radiation exposure and allergies were included. Within the chronic-degenerative diseases, a diagnosis of diabetes, prediabetes, systemic arterial hypertension, dyslipidemia, obesity, overweight was included, and patients with other types of cancer and endocrine diseases (acromegaly, hypoglycemia and Cushing's syndrome) were excluded. A physical examination was performed with measurement of weight, height, BMI, abdominal circumference, waist-hip ratio, systolic and diastolic blood pressure, heart and respiratory rate. The thyroid ultrasound findings were evaluated prior to thyroidectomy, the number of nodules and the largest diameter were included in the analysis. Patients who had a biopsy result prior to thyroidectomy were included in the results according to the Bethesda classification. Paraclinics were requested: HOMA-IR, basal insulin, fasting serum glucose, glycated hemoglobin, complete biochemical profile (triglycerides, total cholesterol, LDL and HDL), complete thyroid profile, thyroglobulin, antithyroglobulin and antiperoxidase antibodies. Regarding the histopathological result, the histological variant (papillary or follicular) was documented, as well as the findings in the case of a benign nodule. In the cases with differentiated thyroid cancer, the size, local vascular, nervous and / or extrathyroid invasion, if unifocal or multifocal, if complete surgical resection was performed, presence of metastatic lymph nodes, distant metastases, TNM clinical stage and risk of recurrence were included in the evaluation. The Insulin Resistance index was established through the HOMA-IR. A value greater than or equal to 2.5 was considered confirmatory of Insulin Resistance. Patients with fasting serum glucose of 70 to $100 \mathrm{mg} / \mathrm{dl}$, and glycosylated hemoglobin <5.7 were considered euglycemic. The prevalence of insulin resistance was calculated in patients with differentiated thyroid cancer and those with benign thyroid nodule, and it was identified whether there are differences between the two groups. Differences in demographic, clinical and biochemical characteristics were analyzed depending on the presence or absence of insulin resistance in patients with differentiated thyroid cancer and those with benign thyroid nodule.

\section{Research Ethics and Patient Consent}

This protocol complies with the research regulations of the General Health Law, the Declaration of Helsinki approved by the World Medical Association in 1947 and its subsequent amendments. It will be carried out in accordance with the ethical and legal principles of good clinical research practices and the current regulations of the Mexican Institute of Social Security, as well as the National Bioethics Commission. The confidentiality of the participants will be guaranteed at all times and the data recorded in the evaluation instruments will be kept in the clinical file. No one else, apart from the researchers, will 
have access to the information, which will be protected by the responsible researcher for a minimum of 5 years.

\section{Statistical methods}

A descriptive analysis of demographic and clinical variables was carried out. The categorical variables were reported as percentages and frequencies; continuous variables were reported as means and standard deviation, or medians and range, according to the population distribution. For comparisons, Student's T or Mann Whitney's U was used for continuous variables. Differences of categorical variables were evaluated with the two-sided Fisher's exact test when two binary variables were contrasted and Pearson's X2 when variables with more than two categories were compared. Factors associated with insulin resistance were analyzed in patients with differentiated thyroid cancer and benign thyroid nodule through multivariate analysis, obtaining odds ratio and 95\% confidence interval. SPSS version 22.0 was used for statistical analysis. A value of $\mathrm{P}<0.05$ was considered significant.

\section{Results}

A total of 52 patients were reviewed, 47 patients corresponded to female gender (90.4\%), with a mean age of 52.04 years ( \pm 15.93). The first group (cases) was made up of euthyroid adult patients who underwent thyroidectomy for the diagnosis of a thyroid nodule with a histopathological result of differentiated thyroid cancer, both papillary and follicular, with a total of 27 patients (51.9\%), of whom 22 were female $(81.5 \%)$ with a mean age of 51.26 years $( \pm 17.09)$. In the second group (controls), patients with benign thyroid nodules confirmed by fine needle aspiration biopsy or with benign results after thyroidectomy were included, made up of 25 patients in this group (48.1\%), all female. (100\%) with a mean age of 52.88 years $( \pm 14.88)$.

Table 1 shows the general characteristics of the patients, as well as the differences depending on the presence or absence of malignancy. Regarding the antecedents, 14 patients $(26.9 \%)$ had a hereditaryfamily history for thyroid disease, being 3 in the first group (11.1\%) and 11 in the second (44\%) (OR 0.159 ; $95 \% \mathrm{Cl} 0.038-0.669 ; \mathrm{p}=0.012)$. In the analysis of the group of patients with a differentiated thyroid cancer outcome, 2 patients had a history of smoking (7.4\%) and 2 of alcoholism (7.4\%), only 1 had a history of radiation exposure (1.9\%). In associated pathologies, 3 patients had type 2 Diabetes Mellitus (11.1\%), 3 had prediabetes (11.1\%) and 9 had arterial hypertension (33.3\%). In anthropometry, the median for Weight was 75kg (66.0-88.0), for Height 1.62m (1.56-1.66) and BMI 29.20 (25.40-32.90), the latter being the most prevalent classifications: Overweight 10 patients (37.0\%) and 8 for Obesity I (29.6\%); Regarding Waist, the median was $97.0 \mathrm{~cm}$ (89.0-110.0), Hip $104.0 \mathrm{~cm}(100.0-115.0)$ with a Waist-Hip Ratio of $0.92(0.88-0.98)$, with 23 patients (85.2\%) being positive.

Regarding the analysis of the group of patients with benign results, 2 patients had a history of smoking $(7.4 \%)$ and 2 of alcoholism (7.4\%), none with a history of radiation exposure. As associated pathologies, 3 patients presented diabetes mellitus type $2(12.0 \%), 2$ prediabetes $(8.0 \%)$ and 5 arterial hypertension 
(20\%), only showing a difference in the prevalence of the last one (33.3\% vs $20.0 \%)$ but without statistical significance. In anthropometry, the median for Weight was $75 \mathrm{~kg}$ (65.0-86.7), for Height 1.60m (1.52-1.62) and BMI 29.40 (26.75-32.65), also with the most prevalent classifications: Overweight 10 patients (40.0\%) and 8 for Obesity I (32.0\%); Regarding Waist, the median was $96.0 \mathrm{~cm}$ (88.0-107.0), Hip $108.0 \mathrm{~cm}$ (99.5115.0) with a Waist-Hip Ratio of 0.91 (0.87-0.94), 22 patients (88.0\%) were positive, showing a prevalence almost similar to the group of cases and without achieving statistical significance in any of the anthropometric data.

In terms of biochemical results, the comparison of the medians between both groups with respect to Insulin was $11.4 \mathrm{ulU} / \mathrm{ml}$ (7.5-14.1) for the case group and $9.1 \mathrm{ulU} / \mathrm{ml}$ (6.1-14.5) for the control group. In the same way, Glucose (94 mg/dL [91-97] vs $95 \mathrm{mg} / \mathrm{dL}$ [89-98]), Glycated hemoglobin (5.2\% [4.9-5.5] vs $5.3 \%$ [4.9-5.5]), Total Cholesterol were compared (189 mg/dL [160-205] vs $185 \mathrm{mg} / \mathrm{dL}$ [161-203]), Triglycerides (152 mg/dL [98-188] vs $151 \mathrm{mg} / \mathrm{dL}$ [109-216]), Thyroglobulin (29.04 ng/ml [16.11-70.75] vs $23.00 \mathrm{ng} / \mathrm{ml}$ [11.55-142.91]), Anti-peroxidase antibodies (7.61 IU/ml [2.83-27.50] vs $14.28 \mathrm{IU} / \mathrm{ml}[1.81-$ 44.08]), Antithyroglobulin (13.10 IU/ml [2.08 -15.15] vs $12.60 \mathrm{IU} / \mathrm{ml}[0.20-26.10]), \mathrm{TSH}(2.93 \mathrm{uUi} / \mathrm{ml}[1.69-$ $3.90]$ vs $2.03 \mathrm{uUi} / \mathrm{ml}$ [1.23-2.63]), HOMA-IR (2.70 [1.60-3.40] vs 2.1 [1.35-3.4]) and with a positive result for HOMA-IR of $15(55.6 \%)$ vs $10(40.0 \%)$ for cases and controls, respectively. Despite the fact that in the HOMA-IR assessment the median in the first group exceeded the cut-off value for considering aist-hip ratio positive, compared with the second group that did not exceed it (2.70 [1.60-3.40] vs 2.1 [1.35-3.4]) not achieving significant results to classify it as a Risk Factor (OR 1.87, 95\% $\mathrm{Cl} 0.038-0.669 ; \mathrm{p}=0.264$ ). Details in Table 2.

Regarding the characteristics of the Thyroid Nodules in the group of cases, a number of Nodules of 1 (1.0-2.5) was found, with a diameter greater than $2.2 \mathrm{~cm}$ (1.7-3.8), and a higher prevalence of TI-RADS 5 with 18 patients $(70.4 \%)$ and Bethesda VI with 9 patients (33.3\%). The most prevalent symptom was foreign body sensation in 10 patients $(37.0 \%)$ Compared with the control group, the number of nodules was 1 (1.0-3.0) and the largest diameter was $2.3 \mathrm{~cm}$ (1.9-3.1), with a higher prevalence of TI-RADS 4 in 12 patients $(48.0 \%$; $=0.036)$ and Bethesda IV in $6(24.0 \% ; p=0.001)$. In this group, the most prevalent associated symptom was foreign body sensation in 13 patients $(52.0 \% ; p=0.278)$. Details in Table 3 .

Based on the group of patients with a malignancy result, a comparison of postsurgical characteristics was made between those patients who had a positive HOMA-IR result with 15 patients and negative with 12. Of the total patients in this group, 23 patients (85.2\%) were in Papillary variant and 4 (14.8\%) Follicular, without significant differences with respect to HOMA-IR $(p=0.809)$. In the HOMA-IR positive group, it was observed that the predominant response to the treatment was incomplete $(40.0 \%)$ with residual structural disease verified by imaging method in 8 patients (23.3\%), unlike the negative group for HOMA-IR the most prevalent response to treatment was excellent and indeterminate with 5 patients $(41.7 \%)$ for both, with only 2 patients $(16.7 \%)$ with residual structural disease, achieving statistical significance only for this last parameter $(p=0.407$ and $P=0.050$, respectively). 
In the HOMA-IR positive group, a greater tendency in the application of lodine-131 with the highest dose of $150 \mathrm{mCi}$ was demonstrated in 10 patients $(71.4 \%)$, as well as statistical significance in local vascular invasion in 8 patients $(53.3 \%)(p=0.078$ and $p=0.014$, respectively), in comparison with the HOMA-IR negative group that showed use of a $100 \mathrm{mCi}$ dose of lodine-131, in 5 patients $(41.7 \%)$ and less local vascular invasion with only 1 patient (8.3\%). Regarding the rest of the characteristics valued as the TNM staging according to the AJCC8, exemplifying with $\mathrm{T} 1 \mathrm{~b}(53.3 \%$ vs $25.2 \%, p=0.227)$, clinical stage I $(60.0 \%$ vs $83.3 \%)$, II (33.3\% vs $8.3 \%)$ and VAT $(6.7 \%$ vs $8.3 \%)(p=0.299)$, high recurrence risk $(26.7 \%$ vs $33.3 \%, p=0.690)$, no statistical significance was found. All these data can be evaluated in detail in Table 4.

Assessing the Risk Factors, significance was found in those patients with a Hereditary Family History of Thyroid Disease (OR 0.159; $95 \% \mathrm{Cl} 0.038-0.669 ; \mathrm{p}=0.012$ ). Risk factors such as positive HOMA-IR (OR 1.870; 95\% Cl 0.622-5.649; $p=0.264)$, Waist / Hip Ratio (OR 0.784; 95\% Cl 0.157-3.911; $p=0.767$ ) or Type 2 Diabetes Mellitus (OR $0.917 ; 95 \% \mathrm{Cl} 0.167-5.026 ; \mathrm{p}=0.920)$ did not conclude to be significant. The rest of the factors analyzed are presented in Table 5. 
Table 1

General characteristics of 52 patients with thyroid nodules classified according to Histopathological result

\begin{tabular}{|c|c|c|c|c|}
\hline Characteristics & Totals & Malignant & Benign & $\mathbf{P}$ \\
\hline$N(\%)$ & $52(100.0)$ & $27(51.9)$ & $25(48.1)$ & \\
\hline Age (years), x ( $\pm S D)$ & $52.04( \pm 15.93)$ & $51.26( \pm 17.09)$ & $52.88( \pm 14.88)$ & 0.718 \\
\hline Gender Female, n (\%) & $47(90.4)$ & $22(81.5)$ & $25(100.0)$ & 0.024 \\
\hline IFH Thyroid disease, n (\%) & $14(26.9)$ & $3(11.1)$ & $11(44.0)$ & 0.008 \\
\hline Hypothyroidism, n (\%) & $7(13.5)$ & $1(3.7)$ & $6(24.0)$ & 0.032 \\
\hline Hyperthyroidism, n (\%) & $1(1.9)$ & $0(0.0)$ & $1(4.0)$ & 0.294 \\
\hline Thyroid nodule, n (\%) & $8(15.4)$ & $2(7.4)$ & $6(24.0)$ & 0.098 \\
\hline Thyroid Cancer, n (\%) & $3(5.8)$ & $2(7.4)$ & $1(4.0)$ & 0.599 \\
\hline Smoking, n (\%) & $6(11.5)$ & $2(7.4)$ & $4(16.0)$ & 0.333 \\
\hline Alcoholism, n (\%) & $6(11.5)$ & $2(7.4)$ & $4(16.0)$ & 0.333 \\
\hline $\begin{array}{l}\text { Exposure to Radiation, } \mathrm{n} \\
(\%)\end{array}$ & $1(1.9)$ & $1(3.7)$ & $0(0.0)$ & 0.331 \\
\hline $\begin{array}{l}\text { Type } 2 \text { diabetes mellitus, } \mathrm{n} \\
(\%)\end{array}$ & $6(11.5)$ & $3(11.1)$ & $3(12.0)$ & 0.920 \\
\hline Treatment, n (\%) & $6 / 6(100.0)$ & $3(100.0)$ & $3(100.0)$ & 0.273 \\
\hline Metformin, n (\%) & $5 / 6(83.3)$ & $2(66.7)$ & $3(100.0)$ & - \\
\hline Sulfonylurea, n (\%) & $1 / 6(16.7)$ & $0(0.0)$ & $1(33.3)$ & - \\
\hline Insulin, n (\%) & $1 / 6(16.7)$ & $1(33.0)$ & $0(0.0)$ & - \\
\hline Prediabetes, n (\%) & $5(9.6)$ & $3(11.1)$ & $2(8.0)$ & 0.704 \\
\hline Hypertension, n (\%) & $14(26.9)$ & $9(33.3)$ & $5(20.0)$ & 0.279 \\
\hline Treatment, n (\%) & $14 / 14(100.0)$ & $9(100.0)$ & $5(100.0)$ & 0.480 \\
\hline ARB, n (\%) & 10/14 (71.4) & 7 (77.8) & $3(60.0)$ & - \\
\hline ACEI, n (\%) & 4/14 (28.6) & $2(22.2)$ & $2(40.0)$ & - \\
\hline $\begin{array}{l}\text { Hashimoto's Thyroiditis, } \mathrm{n} \\
(\%)\end{array}$ & 9 (17.3) & $3(12.0)$ & $6(28.6)$ & 0.158 \\
\hline \multicolumn{5}{|l|}{ Vital signs } \\
\hline SBP (mmHg), med (IQR) & $120(110-130)$ & $120(110-130)$ & $120(110-130)$ & 0.985 \\
\hline $\mathrm{DBP}(\mathrm{mmHg})$, med $(\mathrm{IQR})$ & $80(70-80)$ & $80(70-80)$ & $80(70-81)$ & 0.894 \\
\hline
\end{tabular}




\begin{tabular}{|c|c|c|c|c|}
\hline Characteristics & Totals & Malignant & Benign & $\mathbf{P}$ \\
\hline HR (beat/min), med (IQR) & $77(71-83)$ & $77(72-83)$ & $78(71-82)$ & 0.833 \\
\hline RR (breath/min), med (IQR) & $18(18-20)$ & $18(18-20)$ & $19(18-20)$ & 0.468 \\
\hline $\begin{array}{l}\text { Temperature }\left({ }^{\circ} \mathrm{C}\right) \text {, med } \\
(\text { IQR) }\end{array}$ & $36.2(36.5-36.5)$ & $36.2(36.0-36.5)$ & $36.2(36.0-36.5)$ & 0.254 \\
\hline \multicolumn{5}{|l|}{ Anthropometry } \\
\hline Weight (kg), med (IQR) & $75.0(66.2-87.7)$ & $75(66.0-88.0)$ & $75(65.0-86.7)$ & 0.755 \\
\hline Size (m), med (IQR) & $1.60(1.55-1.64)$ & $1.62(1.56-1.66)$ & $1.60(1.52-1.62)$ & 0.086 \\
\hline BMI (kg/m2), med (IQR) & $\begin{array}{l}29.35(25.95- \\
32.67)\end{array}$ & $\begin{array}{l}29.20(25.40- \\
32.90)\end{array}$ & $\begin{array}{l}29.40(26.75- \\
32.65)\end{array}$ & 0.749 \\
\hline \multicolumn{5}{|l|}{ Body Mass Index } \\
\hline BMI: Normal, n (\%) & $8(15.4)$ & $5(18.5)$ & $3(12.0)$ & 0.980 \\
\hline BMI: Overweight, n (\%) & $20(38.5)$ & $10(37.0)$ & $10(40.0)$ & - \\
\hline BMI: Obesity I, n (\%) & $16(30.8)$ & $8(29.6)$ & $8(32.0)$ & - \\
\hline BMI: Obesity II, n (\%) & $4(7.7)$ & $2(7.4)$ & $2(8.0)$ & - \\
\hline BMI: Obesity III, n (\%) & $4(7.7)$ & $2(7.4)$ & $2(8.0)$ & - \\
\hline $\begin{array}{l}\text { Positive Waist-Hip Ratio, n } \\
\text { (\%) }\end{array}$ & $45(86.5)$ & $23(85.2)$ & $22(88.0)$ & 0.766 \\
\hline Waist-Hip Ratio, med (IQR) & $0.91(0.88-0.94)$ & $0.92(0.88-0.98)$ & $0.91(0.87-0.94)$ & 0.441 \\
\hline Waist (cm), med (IQR) & $96.0(89.0-107.7)$ & $97.0(89.0-110.0)$ & $96.0(88.0-107.0)$ & 0.687 \\
\hline Hip (cm), med (IQR) & $\begin{array}{l}105.0(100.0- \\
114.7)\end{array}$ & $\begin{array}{l}104.0(100.0- \\
115.0)\end{array}$ & $\begin{array}{l}108.0(99.5- \\
115.0)\end{array}$ & 0.783 \\
\hline \multicolumn{5}{|c|}{$\begin{array}{l}\text { Age is expressed as mean } \pm \text { standard deviation. The remaining data are expressed as medians } \\
\text { (minimum-maximum), or absolute frequencies (percentages) }\end{array}$} \\
\hline \multicolumn{5}{|c|}{$\begin{array}{l}\text { SD: Standard Deviation; IFH: Inherited-Family Antecedent; ARB: Angiotensin Receptor Blockers; ACEI: } \\
\text { Angiotensin Converting Enzyme Inhibitor; SBP: Systolic Blood Pressure; DBP: Diastolic Blood } \\
\text { Pressure; med: median; IQR: Inter-Quartile Range; HR: Heart Rate; RR: Respiratory Rate; BMI: Body } \\
\text { Mass Index }\end{array}$} \\
\hline
\end{tabular}


Table 2

Biochemical characteristics of 52 patients with thyroid nodules classified according to Histopathological result

\begin{tabular}{|c|c|c|c|c|}
\hline Laboratory analysis & Totals & Malignant & Benign & $\mathbf{P}$ \\
\hline$N(\%)$ & $52(100.0)$ & $27(51.9)$ & $25(48.1)$ & \\
\hline Insulin (ulU/ml), med (IQR) & $9.4(7.1-14.0)$ & $11.4(7.5-14.1)$ & $9.1(6.1-14.5)$ & 0.458 \\
\hline Glucose (mg/dl), med (IQR) & $94(90-98)$ & $94(91-97)$ & $95(89-98)$ & 0.727 \\
\hline HOMA-IR, med (RIC) & $2.25(1.60-3.37)$ & $\begin{array}{l}2.70(1.60- \\
3.40)\end{array}$ & $2.10(1.35-3.40)$ & 0.503 \\
\hline HOMA-IR Positive, n (\%) & $25(48.1)$ & $15(55.6)$ & $10(40.0)$ & 0.262 \\
\hline $\begin{array}{l}\text { Glycated Hemoglobin (\%), med } \\
\text { (IQR) }\end{array}$ & $5.25(4.90-5.50)$ & $\begin{array}{l}5.20(4.90- \\
5.50)\end{array}$ & $5.30(4.94-5.52)$ & 0.503 \\
\hline $\begin{array}{l}\text { Total Cholesterol }(\mathrm{mg} / \mathrm{dl}) \text {, med } \\
\text { (IQR) }\end{array}$ & $\begin{array}{l}188.5(160.7- \\
188.0)\end{array}$ & $\begin{array}{l}189.0(160.0- \\
205.0)\end{array}$ & $\begin{array}{l}185.0(161.5- \\
203.5)\end{array}$ & 0.749 \\
\hline $\mathrm{HDL}(\mathrm{mg} / \mathrm{dl})$, med (IQR) & $42.5(35.0-51.7)$ & $\begin{array}{l}38.0(33.0- \\
45.0)\end{array}$ & $47.0(36.5-53.0)$ & 0.090 \\
\hline LDL (mg/dl), med (IQR) & $\begin{array}{l}111.5(92.7- \\
132.5)\end{array}$ & $\begin{array}{l}115.0(98.0- \\
137.0)\end{array}$ & $\begin{array}{l}110.0(87.5- \\
125.0)\end{array}$ & 0.220 \\
\hline $\operatorname{VLDL}(\mathrm{mg} / \mathrm{dl})$, med (IQR) & $30.0(21.0-38.0)$ & $\begin{array}{l}30.0(20.0- \\
38.0)\end{array}$ & $30.0(22.0-43.5)$ & 0.452 \\
\hline Triglycerides (mg/dl), med (IQR) & $\begin{array}{l}151.5(102.5- \\
188.0)\end{array}$ & $\begin{array}{l}152.0(98.0- \\
188.0)\end{array}$ & $\begin{array}{l}151.0(109.0- \\
216.5)\end{array}$ & 0.447 \\
\hline $\begin{array}{l}\text { Presurgical Thyroglobulin (ng/ml), } \\
\text { med (IQR) }\end{array}$ & $\begin{array}{l}28.52(15.40- \\
107.87)\end{array}$ & $\begin{array}{l}29.04(16.11- \\
70.75)\end{array}$ & $\begin{array}{l}23.00(11.55- \\
142.91)\end{array}$ & 0.956 \\
\hline Pre-surgical ATg (IU/ml), med (IQR) & $\begin{array}{l}12.85(0.28- \\
17.10)\end{array}$ & $\begin{array}{l}13.10(2.08- \\
15.15)\end{array}$ & $\begin{array}{l}12.60(0.20- \\
26.10)\end{array}$ & 0.956 \\
\hline $\begin{array}{l}\text { Presurgical ATPO (IU/ml), med } \\
\text { (IQR) }\end{array}$ & $\begin{array}{l}8.77(2.28- \\
31.85)\end{array}$ & $\begin{array}{l}7.61(2.83- \\
27.50)\end{array}$ & $\begin{array}{l}14.28(1.81- \\
44.08)\end{array}$ & 0.716 \\
\hline $\begin{array}{l}\text { Pre-surgical TSH (ulU/ml), med } \\
\text { (IQR) }\end{array}$ & $2.22(1.30-3.62)$ & $\begin{array}{l}2.93(1.69- \\
3.90)\end{array}$ & $2.03(1.23-2.63)$ & 0.082 \\
\hline FT4 Presurgical (ng/dl), med (IQR) & $1.01(0.90-1.11)$ & $\begin{array}{l}1.01(0.88- \\
1.10)\end{array}$ & $1.02(0.93-1.12)$ & 0.589 \\
\hline T4T Presurgical (ug/dl), med (IQR) & $8.38(7.13-9.39)$ & $\begin{array}{l}8.47(7.10- \\
8.76)\end{array}$ & $\begin{array}{l}8.29(7.33- \\
10.34)\end{array}$ & 0.595 \\
\hline $\begin{array}{l}\text { FT3 Presurgical }(\mathrm{pg} / \mathrm{ml}) \text {, med } \\
(\text { IQR) }\end{array}$ & $2.62(2.25-2.89)$ & $\begin{array}{l}2.54(2.18- \\
2.88)\end{array}$ & $2.72(2.29-3.12)$ & 0.126 \\
\hline $\begin{array}{l}\text { T3T Presurgical }(\mathrm{ng} / \mathrm{ml}) \text {, med } \\
\text { (IQR) }\end{array}$ & $1.02(0.92-1.18)$ & $\begin{array}{l}1.02(0.92- \\
1.17)\end{array}$ & $1.03(0.92-1.24)$ & 0.539 \\
\hline
\end{tabular}




\section{Laboratory analysis}

Totals

Malignant

Benign

$\mathbf{P}$

Data are expressed as medians (minimum-maximum), or absolute frequencies (percentages)

med: median; IQR: Inter-Quartile Range; HOMA-IR: Homeostasis Model Assessment-Insulin Resistance; HDL: High Density Lipoprotein; LDL: Low Density Lipoprotein; VLDL: Very Low-Density Lipoprotein; ATg: Antithyroglobulin; ATPO: Antiperoxidase; TSH: Thyroid Stimulating Hormone; FT4: Free Thyroxine; T4T: Total Thyroxine; FT3: Free Triiodothyronine; T3T: Total Triiodothyronine 
Table 3

Characteristics of Thyroid Nodules of 52 patients classified according to Histopathological result.

\begin{tabular}{|c|c|c|c|c|}
\hline Characteristic & Totals & Malignant & Benign & $\mathbf{P}$ \\
\hline$N(\%)$ & $52(100.0)$ & $27(51.9)$ & $25(48.1)$ & \\
\hline Number of Nodules, med (IQR) & $1.0(1.0-2.7)$ & $1.0(1.0-2.5)$ & $1.0(1.0-3.0)$ & 0.759 \\
\hline Major diameter (cm), med (IQR) & $2.3(1.8-3.1)$ & $2.2(1.7-3.8)$ & $2.3(1.9-3.1)$ & 0.949 \\
\hline \multicolumn{5}{|l|}{ TI-RADS } \\
\hline $2, n(\%)$ & $1(1.9)$ & $0(0.0)$ & $1(4.0)$ & 0.036 \\
\hline $3, \mathrm{n}(\%)$ & $5(9.6)$ & $1(3.7)$ & $4(16.0)$ & - \\
\hline $4, n(\%)$ & $19(36.5)$ & $7(25.9)$ & $12(48.0)$ & - \\
\hline $5, n(\%)$ & $27(51.9)$ & $18(70.4)$ & $8(32.0)$ & - \\
\hline \multicolumn{5}{|l|}{ Bethesda } \\
\hline $\mathrm{I}, \mathrm{n}(\%)$ & $12(23.1)$ & $6(22.2)$ & $6(24.0)$ & 0.001 \\
\hline II, n (\%) & $9(17.3)$ & $0(0.0)$ & $9(36.0)$ & - \\
\hline III, n (\%) & $3(5.8)$ & $2(7.4)$ & $1(4.0)$ & - \\
\hline IV, n (\%) & $9(17.3)$ & $3(11.1)$ & $6(24.0)$ & - \\
\hline $\mathrm{V}, \mathrm{n}(\%)$ & $10(19.2)$ & $7(25.9)$ & $3(12.0)$ & - \\
\hline VI, n (\%) & $9(17.3)$ & $9(33.3)$ & $0(0.0)$ & - \\
\hline Type of Surgery, n (\%) & $43 / 43(100.0)$ & $27 / 27(100.0)$ & $16(100.0)$ & 0.410 \\
\hline Total thyroidectomy, n (\%) & $36 / 43(83.7)$ & $25 / 27(92.6)$ & $11 / 16(68.8)$ & - \\
\hline Hemithyroidectomy, n (\%) & $7 / 43(16.3)$ & $2 / 27(7.4)$ & $5 / 16(31.3)$ & - \\
\hline \multicolumn{5}{|l|}{ Associated symptoms } \\
\hline Pain, n (\%) & $6(11.5)$ & $4(14.8)$ & $2(8.0)$ & 0.442 \\
\hline Foreign body sensation, $\mathrm{n}(\%)$ & $23(44.2)$ & $10(37.0)$ & $13(52.0)$ & 0.278 \\
\hline Dysphagia, n (\%) & $8(15.4)$ & $2(7.4)$ & $6(24.0)$ & 0.098 \\
\hline Dyspnea, n (\%) & $2(3.8)$ & $1(3.7)$ & $1(4.0)$ & 0.956 \\
\hline Dysphonia, n (\%) & $6(11.5)$ & $3(11.1)$ & $3(12.0)$ & 0.920 \\
\hline \multicolumn{5}{|l|}{ Time of evolution } \\
\hline Less than 6 months, $\mathrm{n}(\%)$ & $6(11.5)$ & $4(14.8)$ & $2(8.0)$ & 0.681 \\
\hline
\end{tabular}




\begin{tabular}{|lllll|}
\hline Characteristic & Totals & Malignant & Benign & P \\
\hline 6 months to 1 year, $\mathrm{n}(\%)$ & $17(32.7)$ & $7(25.9)$ & $10(40.0)$ & - \\
\hline 1-2 years, $\mathrm{n}(\%)$ & $16(30.8)$ & $10(37.0)$ & $6(24.0)$ & - \\
\hline 2-5 years, $\mathrm{n}(\%)$ & $8(15.4)$ & $4(14.8)$ & $4(16.0)$ & - \\
\hline 5-10 years, $\mathrm{n}(\%)$ & $4(7.7)$ & $2(7.4)$ & $2(8.0)$ & - \\
\hline More than 10 years, $\mathrm{n}(\%)$ & $1(1.9)$ & $0(0.0)$ & $1(4.0)$ & - \\
\hline $\begin{array}{l}\text { Data are expressed as medians (minimum-maximum), or absolute frequencies (percentages) } \\
\text { TI-RADS: Thyroid Imaging Report and Data System }\end{array}$ & \\
\hline
\end{tabular}


Table 4

Characteristics of Malignant Tumors of 27 patients classified according to positive or negative HOMA-IR result

\begin{tabular}{|c|c|c|c|c|}
\hline Post-surgical Features & $\begin{array}{l}\text { Total } \\
\text { Malignant }\end{array}$ & $\begin{array}{l}\text { HOMA } \\
\text { Positive }\end{array}$ & $\begin{array}{l}\text { HOMA } \\
\text { Negative }\end{array}$ & $\mathbf{P}$ \\
\hline$N(\%)$ & $27(100.0)$ & $15(100.0)$ & $12(100.0)$ & \\
\hline Stimulated thyroglobulin, n (\%) & $7(30.4)$ & $4(30.8)$ & $3(30.8)$ & 0.968 \\
\hline \multicolumn{5}{|l|}{ Answer } \\
\hline Excellent, n (\%) & $10(37.0)$ & $5(33.3)$ & $5(41.7)$ & 0.407 \\
\hline Indeterminate, n (\%) & $9(33.3)$ & $4(26.7)$ & $5(41.7)$ & - \\
\hline Incomplete, $\mathrm{n}(\%)$ & $8(29.6)$ & $6(40.0)$ & $2(16.7)$ & - \\
\hline Residual Structural Disease, $\mathrm{n}(\%)$ & $10(37.0)$ & $8(23.3)$ & $2(16.7)$ & 0.050 \\
\hline lodine application, n (\%) & $26(96.3)$ & $14(93.3)$ & $12(100.0)$ & 0.362 \\
\hline lodine-131 dose, n (\%) & $26(96.3)$ & & & \\
\hline 30 (mCi), n (\%) & $6(23.1)$ & $3(21.4)$ & $3(25.0)$ & 0.078 \\
\hline 100 (mCi), n (\%) & $6(23.1)$ & $1(7.1)$ & $5(41.7)$ & - \\
\hline 150 (mCi), n (\%) & $14(53.8)$ & $10(71.4)$ & $4(33.3)$ & - \\
\hline $\begin{array}{l}\text { Post-surgical time for lodine-131, n } \\
(\%)\end{array}$ & $26(96.3)$ & & & \\
\hline 2 months, n (\%) & $5(19.2)$ & $4(28.6)$ & $1(8.3)$ & 0.192 \\
\hline 3 months, n (\%) & $21(80.8)$ & $10(71.4)$ & $11(91.7)$ & - \\
\hline \multicolumn{5}{|l|}{ Cancer type, n (\%) } \\
\hline Papillary, n (\%) & $23(85.2)$ & $13(86.7)$ & $10(83.3)$ & 0.809 \\
\hline Follicular, n (\%) & $4(14.8)$ & $2(13.3)$ & $2(16.7)$ & - \\
\hline \multicolumn{5}{|l|}{ TNM staging (AJCC8), n (\%) } \\
\hline T1a, n (\%) & $3(11.1)$ & $1(6.7)$ & $2(16.7)$ & 0.277 \\
\hline T1b, n (\%) & $11(40.7)$ & $8(53.3)$ & $3(25.0)$ & - \\
\hline $\mathrm{T} 2, \mathrm{n}(\%)$ & $5(18.5)$ & $1(6.7)$ & $4(33.3)$ & - \\
\hline T3a, n (\%) & $2(7.4)$ & $1(6.7)$ & $1(8.3)$ & - \\
\hline T3b, n (\%) & $2(7.4)$ & $2(13.3)$ & $0(0.0)$ & - \\
\hline T4a, n (\%) & $3(11.1)$ & $1(6.7)$ & $2(16.7)$ & - \\
\hline
\end{tabular}




\begin{tabular}{|c|c|c|c|c|}
\hline Post-surgical Features & $\begin{array}{l}\text { Total } \\
\text { Malignant }\end{array}$ & $\begin{array}{l}\text { HOMA } \\
\text { Positive }\end{array}$ & $\begin{array}{l}\text { HOMA } \\
\text { Negative }\end{array}$ & $P$ \\
\hline T4b, n (\%) & $1(3.7)$ & $1(6.7)$ & $0(0.0)$ & - \\
\hline No, n (\%) & $21(77.8)$ & $10(66.7)$ & $11(91.7)$ & 0.121 \\
\hline N1, n (\%) & $6(22.2)$ & $5(33.3)$ & $1(8.3)$ & - \\
\hline M0, n (\%) & $27(100.0)$ & $15(100.0)$ & $12(100.0)$ & - \\
\hline \multicolumn{5}{|l|}{ Clinical Stage, n (\%) } \\
\hline $\mathrm{I}, \mathrm{n}(\%)$ & $19(70.4)$ & $9(60.0)$ & $10(83.3)$ & 0.299 \\
\hline II, n (\%) & $6(22.2)$ & $5(33.3)$ & $1(8.3)$ & - \\
\hline Ivan (\%) & $2(7.4)$ & $1(6.7)$ & $1(8.3)$ & - \\
\hline \multicolumn{5}{|l|}{ Risk of Recurrence, n (\%) } \\
\hline Low, n (\%) & $15(55.6)$ & $8(53.3)$ & $7(58.3)$ & 0.690 \\
\hline Intermediate, n (\%) & $4(14.8)$ & $3(20.0)$ & $1(8.3)$ & - \\
\hline High, n (\%) & $8(29.6)$ & $4(26.7)$ & $4(33.3)$ & - \\
\hline Local vascular invasion, n (\%) & $9(33.3)$ & $8(53.3)$ & $1(8.3)$ & 0.014 \\
\hline Local nerve invasion, n (\%) & $1(3.7)$ & $0(0.0)$ & $1(8.3)$ & 0.255 \\
\hline Extrathyroid Extension, n (\%) & $5(18.5)$ & $3(20.0)$ & $2(16.7)$ & 0.825 \\
\hline \multicolumn{5}{|l|}{ Focality, n (\%) } \\
\hline Unifocal, n (\%) & $15(55.6)$ & $9(60.0)$ & $6(50.0)$ & 0.603 \\
\hline Multifocal, n (\%) & $12(44.4)$ & $6(40.0)$ & $6(50.0)$ & - \\
\hline Complete resection, $\mathrm{n}(\%)$ & $25(92.6)$ & $14(93.3)$ & $11(91.7)$ & 0.869 \\
\hline Resected lymph nodes, n (\%) & $12(44.4)$ & $8(53.3)$ & $4(33.3)$ & 0.299 \\
\hline Positive ganglia, n (\%) & $7(58.3)$ & $5(62.5)$ & $5(50)$ & 0.679 \\
\hline \multicolumn{5}{|c|}{ Data are expressed in absolute frequencies (percentages) } \\
\hline TNM: Tumor-Node-Metastase & Editio & & & \\
\hline
\end{tabular}


Table 5

Assessment of Risk Factors

\begin{tabular}{|llll|}
\hline Risk factors & OR & 95\% Cl & P \\
\hline IFH for Thyroid Disease & 0.159 & $0.038-0.669$ & 0.012 \\
\hline Insulin Resistance x HOMA-IR & 1.870 & $0.622-5.649$ & 0.264 \\
\hline Overweight x BMI & 0.882 & $0.288-2.699$ & 0.826 \\
\hline Obesity x BMI & 0.867 & $0.291-2.582$ & 0.797 \\
\hline Waist/Hip Ratio & 0.784 & $0.157-3.911$ & 0.767 \\
\hline Hypertriglyceridemia & 1.273 & $0.423-3.831$ & 0.668 \\
\hline Hypercholesterolemia & 1.286 & $0.393-4.202$ & 0.677 \\
\hline Smoking & 0.420 & $0.070-2.525$ & 0.343 \\
\hline Diabetes mellitus & 0.917 & $0.167-5.026$ & 0.920 \\
\hline Prediabetes & 1.437 & $0.220-9.405$ & 0.705 \\
\hline Arterial hypertension & 2.000 & $0.564-7.087$ & 0.283 \\
\hline \begin{tabular}{l} 
The data obtained are expressed in Odds-Ratio, $95 \%$ Confidence Interval and significant p value \\
\hline C.050
\end{tabular} HOMA-IR: Homeostasis Model Assessment-Insulin Resistance; BMl: Body Mass Index & \\
\hline
\end{tabular}

\section{Discussion}

In the present trial, patients with a history of Thyroid Nodules classified according to histopathological results in a group of malignant (cases) or benign (controls) were evaluated, to later assess their relationship with respect to different Anthropometric parameters: Weight, Height, BMI, Waist/Hip Ratio, among others; Biochemicals: Insulin, Glucose, HOMA-IR, Glycated Hemoglobin, Cholesterol, Triglycerides and parameters of the Thyroid Profile; in addition to the characteristics of Thyroid Nodules. A final analysis is in which the relationship of Malignant Tumors with those patients with positive or negative HOMA-IR was assessed.

According to the analysis obtained, there is a greater tendency to a higher HOMA IR in patients who have cancer, without reaching statistical significance. Different cross-sectional studies designed to evaluate the prevalence of insulin resistance in subjects with benign thyroid nodules compared to controls, demonstrated a higher prevalence of thyroid nodules in subjects with insulin resistance by evaluation with HOMA-IR. Evidence suggests that IGF-I and TSH-dependent signaling play a role in regulating the growth of the human thyroid gland. ${ }^{11}$ 
In 2018 a meta-analysis of associations between nosological entities with differentiated thyroid cancer, studied: dyslipidemia, metabolic syndrome, arterial hypertension, diabetes mellitus, and insulin resistance. Patients with type 2 diabetes mellitus, arterial hypertension, and insulin resistance presented a significant risk of cancer, being the last one with the highest risk estimate. Some reasons why statistical significance was not achieved and should be considered for future studies are insufficient sample size, age of the patients or factors that influence insulin resistance, such as prevalence of similar obesity, diabetes mellitus, prediabetes, waist/hip ratio or use of different cut-off points for HOMA-IR. ${ }^{12}$

Patients with a family history of thyroid disease, those with hypothyroidism at diagnosis and/or with positive antibodies appear to be less likely to have malignancy. Regarding family history, the current evidence is contrasting because, among the risk factors, this history is attributed an OR of 2.29, being the most prominent in various literature. Of particular importance are germline variations on chromosomes 9q22.33 and 14q13.3 associated with a high risk of differentiated thyroid cancer. This aspect is worth studying with a larger study sample. ${ }^{13}$

Brenta et al. observed that patients with hypothyroidism, compared to euthyroid subjects, showed a significantly lower glucose utilization during a short intravenous insulin tolerance test, on par with lower insulin levels, which would explain a lower proliferative stimulus in thyroid cells, supporting our finding of hypothyroidism as a protective factor. ${ }^{14}$

As expected, patients with higher Bethesda or TI-RADS were more likely to be malignancies. The literature indicates that the onset and speed of progression of symptoms are important in terms of thyroid cancer risk, as persistent dysphonia and rapidly growing thyroid nodules are more likely to indicate a malignant cause. The previous valid arguments due to the fact that greater proliferative stimulation by insulin mediators will contribute to a greater tumor mass and therefore the appearance of symptoms, however, we do not conclude differences with these aspects, because the cellular stimulation by these mediators is the same in malignant and not malignant masses and therefore there must be a trigger that guides the cells to take malignant lines, which may be higher rates of insulin resistance than those used in the present study, which would be worth considering taking into account in future analyzes. ${ }^{14}$

Patients with insulin resistance were classified with a similar risk of recurrence, however, it seems that there is a greater tendency to residual structural disease, indication of higher doses of iodine, more advanced clinical stage and positive lymph nodes, although not significant. In the literature investigated, there is no reference to the assessment of the aforementioned characteristics in relation to insulin resistance, the approach is direct to whether or not there is an association with thyroid cancer. The only data to consider relevant in the literature is the fact that a greater tendency for insulin resistance was found to be associated with the follicular variant, however, it does not contribute relevance because the higher prevalence of papillary over follicular thyroid cancer is somewhat widely already described. ${ }^{12}$

Regarding local vascular invasion, the positive HOMA-IR group had statistical significance. We consider the pathophysiological principle that IGF-I and TSH-dependent signaling play an important role in the 
regulation of growth, both of the thyroid gland and thyroid nodules and, therefore, a greater probability of malignant pathology, it is expected that patients in this group show tumor characteristics with greater structural and biochemical compromise. However, refer to what was mentioned in previous lines, regarding the lack of information in the literature on the relationship between insulin resistance and invasion of local structures. ${ }^{11}$

It should be noted the limitations presented in the study, such as the lack of a larger sample number and the difficulties that this implies due to the current health contingency worldwide caused by the COVID-19 pandemic. Also consider the HOMA-IR cut-off points for the Mexican population. Although positive HOMA-IR was not related to a greater predisposition to the appearance of Cancer, a greater tendency of characteristics of poorer post-surgical prognosis was observed, so a future analysis with a larger sample size would help to better discern future result.

\section{Declarations}

\section{Funding Source:}

Not applicable

\section{Conflict-of-Interest:}

Not applicable

\section{Data availability:}

Not applicable

\section{Code availability:}

SPSS version 22.0

\section{Authors' contributions:}

All authors agreed with the content

\section{References}

1. Djiogue S, Nwabo Kamdje AH, Vecchio L, Kipanyula MJ, Farahna M, Aldebasi Y, et al. Insulin resistance and cancer: the role of insulin and IGFs. Endocr Relat Cancer. 2013;20(1):R1-17. 
2. Manzella L, Massimino M, Stella S, Tirrò E, Pennisi MS, Martorana F, et al. Activation of the IGF Axis in Thyroid Cancer: Implications for Tumorigenesis and Treatment. Int J Mol Sci. 2019;20(13):3258.

3. Vella V, Malaguarnera R. The Emerging Role of Insulin Receptor Isoforms in Thyroid Cancer: Clinical Implications and New Perspectives. Int J Mol Sci. 2018;19(12):3814.

4. Tzivion G, Dobson M, Ramakrishnan G. FoxO transcription factors; Regulation by AKT and 14-3-3 proteins. Biochim Biophys Acta. 2011;1813(11):1938-45.

5. Fleming HE, Janzen V, Lo Celso C, Guo J, Leahy KM, Kronenberg HM, et al. Wnt signaling in the niche enforces hematopoietic stem cell quiescence and is necessary to preserve self-renewal in vivo. Cell Stem Cell. 2008;2(3):274-83.

6. Artim SC, Mendrola JM, Lemmon MA. Assessing the range of kinase autoinhibition mechanisms in the insulin receptor family. Biochem J. 2012;448(2):213-20.

7. Oberman B, Khaku A, Camacho F, Goldenberg D. Relationship between obesity, diabetes and the risk of thyroid cancer. Am J Otolaryngol. 2015;36(4):535-41.

8. Cho YY, Kang MJ, Kim SK, Jung JH, Hahm JR, Kim TH, et al. Protective Effect of Metformin Against Thyroid Cancer Development: A Population-Based Study in Korea. Thyroid. 2018;28(7):864-70.

9. Heidari Z, Mashhadi MA, Nosratzehi S. Insulin Resistance in Patients with Benign Thyroid Nodules. Arch Iran Med. 2015;18(9):572-6.

10. Saghier AE, Bassit Hassan EO, Ahmed Shawky ZA. AM. Euthyroid nodular disease in relation to insulin resistance. Int J Diabetes Res. 2015;4(3):49-57.

11. Rezzonico J, Rezzonico M, Pusiol E, Pitoia F, Niepomniszcze H. Introducing the thyroid gland as another victim of the insulin resistance syndrome. Thyroid. 2008;18(4):461-4.

12. Yin DT, He H, Yu K, Xie J, Lei M, Ma R, et al. The association between thyroid cancer and insulin resistance, metabolic syndrome and its components: A systematic review and meta-analysis. Int $\mathrm{J}$ Surg. 2018;57:66-75.

13. Singh Ospina N, Iñiguez-Ariza NM, Castro MR. Thyroid nodules: diagnostic evaluation based on thyroid cancer risk assessment. BMJ. 2020 Jan 7;368:16670.

14. Gierach M, Gierach J, Junik R. Insulin resistance and thyroid disorders. Endokrynol Pol. 2014;65(1):70-6. 